\title{
Effect of Low Temperature Annealing on Microstructural and Optical Properties of $\left(\mathrm{BaTiO}_{3}\right)_{0.84}\left(\mathrm{CeO}_{2}\right)_{0.16}$ Thin Films
}

\author{
Z.H. Dughaish*
}

Physics Department, College of Science, Qassim University, P.O. 6644, Buraidah 51452, Saudi Arabia

(Received December 24, 2011; in final form October 11, 2012)

$\left(\mathrm{BaTiO}_{3}\right)_{0.84}\left(\mathrm{CeO}_{2}\right)_{0.16}$ thin films were prepared by electron beam evaporation method. X-ray diffraction and scanning electron microscopy revealed the amorphous structure for the as-prepared films. The thin films were annealed at temperatures: 200, 300, 400 and $500{ }^{\circ} \mathrm{C}$ for $1 \mathrm{~h}$ in air. Small and low intensity crystalline peaks were observed at annealing temperature of $200^{\circ} \mathrm{C}$ for $1 \mathrm{~h}$. The intensity and the number of the crystalline peaks were increased with increasing annealing temperature. Nanocrystals, of dimensions in the range $60-76 \mathrm{~nm}$, were obtained when the annealing was performed at $500{ }^{\circ} \mathrm{C}$. The indexed diffraction pattern of the annealed thin film revealed a monoclinic structure. A two-layer model was used to describe the experimental ellipsometric data. The Bruggeman effective medium approximation was used to describe the surface roughness layer and the Cauchy dispersion relation was used to describe the main $\left(\mathrm{BaTiO}_{3}\right)_{0.84}\left(\mathrm{CeO}_{2}\right)_{0.16}$ layer. The optical constants of the thin films over 300-1100 $\mathrm{nm}$ spectral range were measured. The optical band gap showed gradual decrease with the annealing temperature. The accurate determination of the optical constants of the thin films is very useful and should be taken into consideration in the design of devices using optical thin films technology.

DOI: $10.12693 /$ APhysPolA.123.87

PACS: 68.55.-a, 77.55.F-, 78.20.Ci, 78.66.-w, 81.15.-z, 81.40.Ef, 81.70.Fy

\section{Introduction}

Barium titanate $\left(\mathrm{BaTiO}_{3}\right)$ has recently gained much attention due to its high dielectric constant, ferroelectric activity, spontaneous polarization and nonlinear optical properties in both active and passive electronic components [1-4]. The influences of transition metal oxides and rare-earth oxides dopants on properties of $\mathrm{BaTiO}_{3}$ have been investigated in order to improve its properties and widen its applications $[5,6]$. In particular, mixing $\mathrm{BaTiO}_{3}$ with $\mathrm{CeO}_{2}$ could produce superior properties. Jones and Jaatinen [7] stated that $\mathrm{Ce}: \mathrm{BaTiO}_{3}$ exhibit a light induced change in refractive index, and have potential uses in many areas of optical communications and circuitry. The results show that it is possible to obtain both intensity dependent absorption and transparency in $\mathrm{Ce}: \mathrm{BaTiO}_{3}$ at different wavelengths. Cernea et al. [8] observed that dielectric ceramics of $\mathrm{Ce}: \mathrm{BaTiO}_{3}$ present practical interest because addition of cerium decreases significantly the Curie temperature $\left(T_{\mathrm{C}}\right)$ of $\mathrm{BaTiO}_{3}$. Issa et al. [9] and Dughaish and Issa [10] showed that addition of low concentrations less than 5 mol. $\% \mathrm{CeO}_{2}$ to $\mathrm{BaTiO}_{3}$ lattice lowered $T_{\mathrm{C}}$ and the addition of $16 \mathrm{~mol} . \% \mathrm{CeO}_{2}$ to $\mathrm{BaTiO}_{3}$ smeared out $T_{\mathrm{C}}$ and changed the structure from tetragonal phase into cubic phase at room temperature. This guided us to choose this system for this study because it has electrical permittivity higher than that of pure barium titanate, and its crystal structure (cubic [9]) will not change during operation since there is no transition temperature (the addition of $\mathrm{CeO}_{2}$ smeared out the transition temperature $T_{\mathrm{C}}[10]$ ) and looks promising to have wide applications in electronics, optoelectronics, and gas sensing applications.

*e-mail: zhdalmas45@gmail.com

\section{Experimental details}

$\left(\mathrm{BaTiO}_{3}\right)_{0.84}\left(\mathrm{CeO}_{2}\right)_{0.16}$ system was prepared by mixing the appropriate quantities of high purity $\mathrm{CeO}_{2}$ and $\mathrm{BaTiO}_{3}$ by the usual ceramic method. The $16 \mathrm{~mol} . \%$ batch was dry mixed in an agate ball mill for $1 \mathrm{~h}$, calcined in platinum crucibles at $800^{\circ} \mathrm{C}$ for $2 \mathrm{~h}$. The calcined lumps were ground by a mortar and pestle, pressed at $4 \times 10^{7} \mathrm{~kg} \mathrm{~m}^{-2}$ into pellets of $1.2 \mathrm{~cm}$ in diameter and about $0.15 \mathrm{~cm}$ in thickness. The pellets were fired at $1360{ }^{\circ} \mathrm{C}$ in a muffle furnace for $2 \mathrm{~h}$ in air, and cooled down to room temperature inside the furnace.

The thin films of $\left(\mathrm{BaTiO}_{3}\right)_{0.84}\left(\mathrm{CeO}_{2}\right)_{0.16}$ were prepared by electron beam evaporation, since it gives a high deposition rate and good film quality, using high vacuum coating unit type Edward 306 A. The system was pumped down to a pressure of $5 \times 10^{-6}$ mbar. $\left(\mathrm{BaTiO}_{3}\right)_{0.84}\left(\mathrm{CeO}_{2}\right)_{0.16}$ pellet was degassed prior the start of the evaporation process by heating in a vacuum chamber with an electron gun. The films were deposited on pre-cleaned microscopic glass slides and one side polished Si (100) substrates. The substrates were carefully cleaned by using acetone and distilled water. The substrates were rotating during the deposition. The source to substrate distance was $20 \mathrm{~cm}$ and the deposition rate was about $4 \mathrm{~nm} / \mathrm{s}$. Film thicknesses and the rate of evaporation were monitored with a quartz crystal monitor attached to the vacuum system.

The microstructural and optical properties of the e-beam evaporated $\left(\mathrm{BaTiO}_{3}\right)_{0.84}\left(\mathrm{CeO}_{2}\right)_{0.16}$ thin films were characterized by X-ray diffraction (XRD), scanning electron microscope (SEM), energy dispersive analysis of X-ray (EDAX) and spectroscopic ellipsometry (SE). The SEM, EDAX and the ellipsometric measurements were carried out for samples prepared on $\mathrm{Si}$ (100) and the XRD measurements were carried out on glass substrates. Investigations of the crystal structure were carried out 
by a Shimadzu Diffractometer XRD 6000, Japan, with $\mathrm{Cu} K_{\alpha_{1}}$ radiation $(\lambda=1.54056 \AA)$. The data collection was performed by step-scan modes, in a $2 \theta$ range between $10^{\circ}$ and $75^{\circ}$ with step-size of $0.02^{\circ}$ and step time of 0.6 s. Pure silicon $(\approx 99.9999 \%)$ was used as an internal standard.

The surface morphology and crystal structure of the films were characterized by SEM type JOEL model JSM-6380 LA (Japan). The chemical composition of the films was analyzed using energy dispersive analysis of X-ray (EDAX) unit attached to the SEM.

Variable angle spectroscopic ellipsometry (VASE) data for $\left(\mathrm{BaTiO}_{3}\right)_{0.84}\left(\mathrm{CeO}_{2}\right)_{0.16}$ films prepared on $\mathrm{Si}(100)$ were obtained using a PHE-102 variable angle spectroscopic ellipsometer (Angstrom Advanced Inc.) in the wavelength range $300-1100 \mathrm{~nm}$. The data were obtained at angles of incidence of $70^{\circ}$ and $75^{\circ}$. The instrument measures the complex ratio of the Fresnel reflection coefficients for $p$ - and $s$-polarized light and reports the ratio in terms of the ellipsometric parameters $\Psi$ and $\Delta$ defined by the equation

$$
F=\tan (\Psi) \exp (\mathrm{i} \Delta)=\frac{\tilde{r}_{p}}{\tilde{r}_{s}},
$$

$\tilde{r}_{p}, \tilde{r}_{s}$ are the amplitude reflection coefficients for light polarized in the $p$ - and $s$-planes of incidence, respectively. The data obtained from the ellipsometer were accurately modeled using the PHE-102 software package. Ellipsometric data $\Psi$ and $\Delta$ for variable wavelengths were fitted in the optical model.

The $\left(\mathrm{BaTiO}_{3}\right)_{1-0.16}\left(\mathrm{CeO}_{2}\right)_{0.16}$ thin films were annealed at $200,300,400$ and $500{ }^{\circ} \mathrm{C}$ in a muffle furnace for $1 \mathrm{~h}$ in air. XRD and VASE were used to characterize the films, before and after the annealing process, by following the previously mentioned procedures.

\section{Results and discussion}

\subsection{EDAX, XRD, and SEM examinations}

The results of the EDAX analysis for $\left(\mathrm{BaTiO}_{3}\right)_{1-0.16}\left(\mathrm{CeO}_{2}\right)_{0.16}$ grown on $\mathrm{Si}$ (100) substrates revealed that all the elements: $\mathrm{Ba}, \mathrm{Ti}, \mathrm{Ce}$ and $\mathrm{O}$ are present. Normalizing the atomic percentages to the $\mathrm{Ti}$ ratio gives the composition $\mathrm{Ba}_{0.96} \mathrm{TiCe}_{0.29} \mathrm{O}_{5.37}$ for the as-prepared film which indicates a lower Ba content. This reduction in $\mathrm{Ba}$ has been previously reported $[11,12]$. Upon annealing and within a precision of 2 at.\%, the EDAX analysis does not reveal any obvious change in the chemical composition of the films.

The X-ray diffraction patterns, of the $\left(\mathrm{BaTiO}_{3}\right)_{0.84}\left(\mathrm{CeO}_{2}\right)_{0.16}$ thin films, annealed at different temperatures are shown in Fig. 1a-e. The X-ray diffraction pattern of the as-prepared film (see Fig. 1a) contains no peaks which imply the amorphous structure. Crystalline peak at $2 \theta$ of $24^{\circ}$ is observed after annealing the film at $200^{\circ} \mathrm{C}$ for $1 \mathrm{~h}$ (see Fig. 1b). The crystallization increased through the film as the annealing temperature is increased, Fig. 1c,d, and became clearer. From the JCDPS files, the diffraction peaks can be identified as monoclinic barium titanium oxide $\left(\mathrm{Ba}_{6} \mathrm{Ti}_{7} \mathrm{O}_{40}\right)$ (JCDPS card no. 77-1566). It is worth mentioning that the $\mathrm{BaTiO}_{3}$ ceramic source had tetragonal phase of stoichiometric $\mathrm{BaTiO}_{3}$ (figure is not shown). $\mathrm{CeO}_{2}$ peaks are not found in XRD pattern, which imply that $\mathrm{Ce}$ atoms replace $\mathrm{Ba}$ in the monoclinic lattice or segregate to the non-crystalline regions in the grain boundaries. Fasasi et al. [13] observed a similar absence of $\mathrm{ZnO}$ in XRD pattern of $\mathrm{ZnO}$-doped $\mathrm{BaTiO}_{3}$ grown by laser ablation and annealed at $550^{\circ} \mathrm{C}$ for $12 \mathrm{~h}$.

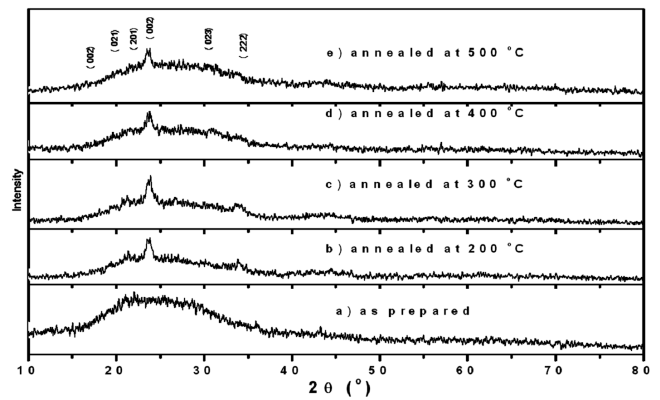

Fig. 1. XRD patterns of $\left(\mathrm{BaTiO}_{3}\right)_{0.84}\left(\mathrm{CeO}_{2}\right)_{0.16}$ thin films annealed at different temperatures.

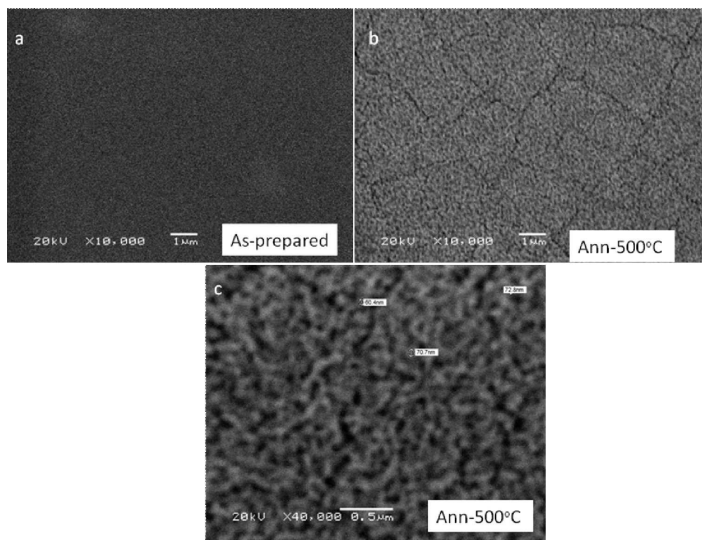

Fig. 2. SEM images of $\left(\mathrm{BaTiO}_{3}\right)_{0.84}\left(\mathrm{CeO}_{2}\right)_{0.16}$ thin films; (a) as-prepared; (b) and (c) low and high magnifications of the film annealed at $500{ }^{\circ} \mathrm{C}$, respectively.

Figure $2 \mathrm{a}-\mathrm{c}$ shows the SEM images of the as-prepared and annealed $\left(\mathrm{BaTiO}_{3}\right)_{0.84}\left(\mathrm{CeO}_{2}\right)_{0.16}$ thin films on $\mathrm{Si}$ (100) substrates. The micrograph of the as-prepared film (see Fig. 2a) shows a uniform film and smooth surface which confirms the amorphous structure. The film annealed at $500{ }^{\circ} \mathrm{C}$ shows obvious crystals with obvious grain boundaries (Fig. $2 \mathrm{~b}$ and c). The obtained nanocrystals have dimensions in the range 60-76 nm (Fig. 2b).

\subsection{Ellipsometric investigations}

In order to estimate the optical constants of the $\left(\mathrm{BaTiO}_{3}\right)_{0.84}\left(\mathrm{CeO}_{2}\right)_{0.16}$ thin films, the ellipsometric spectra were analyzed by a multilayer modeling of a 
two layer model (surface roughness layer and main $\left(\mathrm{BaTiO}_{3}\right)_{0.84}\left(\mathrm{CeO}_{2}\right)_{0.16}$ layer $)$. The optical constants of Si obtained by Herzinger et al. [14] were used for the substrate. The complex refractive index of the surface roughness layer (SRL) was calculated by the Bruggeman effective medium approximation (BEMA) assuming a mixture of the "Lorenz oscillator-material" and a fitted percentage (volume fraction) of voids (air). The complex refractive index of the film was described by Cauchy model. The Cauchy dispersion relation can be expressed as

$$
\begin{aligned}
& n(\lambda)=A_{n}+\frac{B_{n}}{\lambda^{2}}+\frac{C_{n}}{\lambda^{4}}, \\
& k(\lambda)=\alpha^{\prime} \exp \left(B\left(\frac{1}{\lambda}-\frac{1}{\lambda_{0}}\right)\right) .
\end{aligned}
$$

The six parameters in this dispersion model are $A_{n}, B_{n}$, $C_{n}$, the extinction coefficient amplitude $\alpha^{\prime}$, the exponent factor $\beta$, and the wavelength corresponding to the band gap value $\lambda_{0}$. All the Cauchy six parameters, the thickness and the voids fraction of the BEMA surface layer and the thickness of the interface layer were used as variable fit parameters. The fit to SE data at $70^{\circ}$ and $75^{\circ}$ incident angles were performed simultaneously. An example for the best fit of the experimental $\Psi$ and $\Delta$ of the $\left(\mathrm{BaTiO}_{3}\right)_{0.84}\left(\mathrm{CeO}_{2}\right)_{0.16}$ films is shown in Fig. 3a and b. It is seen that there is a good agreement between the simulated and the measured data. Therefore, the optical constants can be adequately extracted. The presence of the interference patterns over the whole wavelength range is indicating that the films are transparent in the region. The thicknesses of the layers determined by VASE data fits are summarized in Table I. The surface roughness thickness is increased with increase of the annealing temperature. The thickness remains practically constant upon annealing at $200{ }^{\circ} \mathrm{C}$. Annealing at $300^{\circ} \mathrm{C}$ caused decrease in thickness. The increase in surface roughness and the decrease in thickness are associated with the crystallization [15].

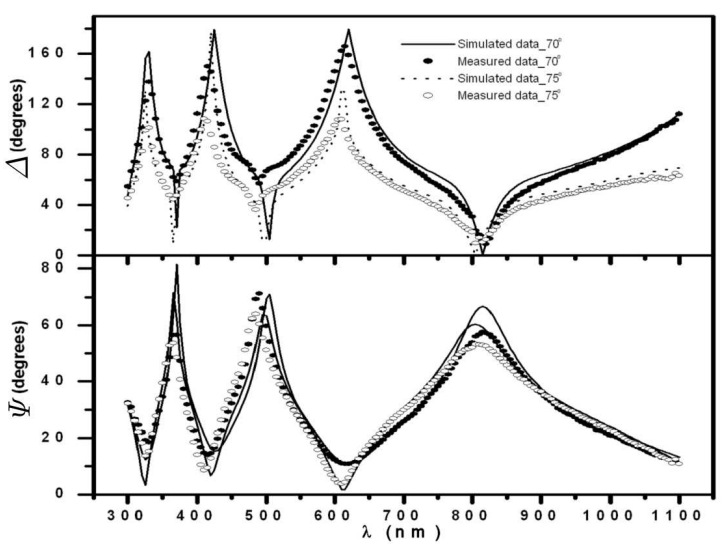

Fig. 3. Experimental and calculated ellipsometric parameters $\Psi$ and $\Delta$ taken at angles of incidence $70^{\circ}$ and $75^{\circ}$. The spectra are for the film annealed at $300^{\circ} \mathrm{C}$.

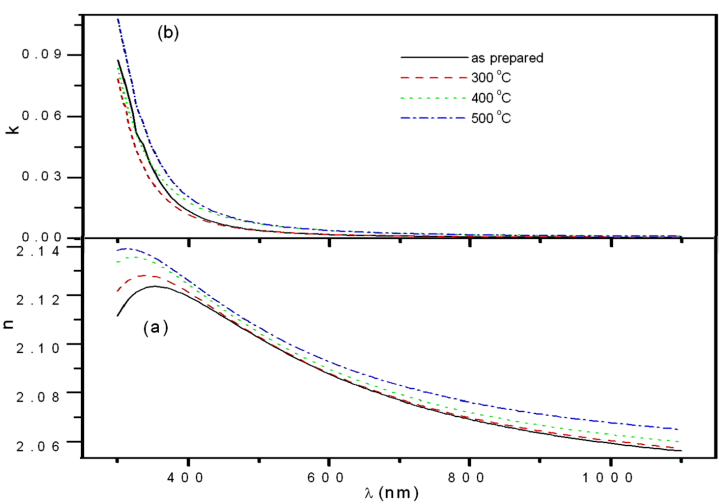

Fig. 4. (a) Refractive index $n$ as a function of wavelength $\lambda$ of $\left(\mathrm{BaTiO}_{3}\right)_{0.84}\left(\mathrm{CeO}_{2}\right)_{0.16}$ films annealed at different temperatures. (b) Extinction coefficient $k$ as a function of wavelength $\lambda$ of $\left(\mathrm{BaTiO}_{3}\right)_{0.84}\left(\mathrm{CeO}_{2}\right)_{0.16}$ films annealed at different temperatures.

TABLE I

Thickness derived from the ellipsometric data fitting (main/superficial layer) and optical band gap $\left(E_{\mathrm{g}}\right)$.

\begin{tabular}{r|c|c}
\hline \hline $\begin{array}{l}\text { Annealing } \\
\text { temperature }\left[{ }^{\circ} \mathrm{C}\right]\end{array}$ & $\begin{array}{c}\text { Thickness }[\mathrm{nm}] \\
(\text { main layer/SRL) }\end{array}$ & $E_{\mathrm{g}}[\mathrm{eV}]$ \\
\hline as-prepared & $453.4 / 7.1$ & 3.68 \\
200 & $453.5 / 6.5$ & 3.71 \\
300 & $452.4 / 7.4$ & 3.75 \\
400 & $450.8 / 7.9$ & 3.67 \\
500 & $449.2 / 8.5$ & 3.65
\end{tabular}

The obtained optical constants $n$ and $k$ of the $\left(\mathrm{BaTiO}_{3}\right)_{0.84}\left(\mathrm{CeO}_{2}\right)_{0.16}$ are shown in Fig. 4a and b, respectively. The refractive index follows a normal dispersion behavior with wavelength where it decreases as the wavelength increases. The refractive index $n$ increases with increase of the annealing temperature. This can be ascribed, as previously reported for other oxides, to the increase in the density with increasing annealing temperature [15]. The extinction coefficient $k$ values of the $\left(\mathrm{BaTiO}_{3}\right)_{0.84}\left(\mathrm{CeO}_{2}\right)_{0.16}$ films, annealed at different temperatures, are close to zero over most of the studied wavelength range, and increases rapidly at the short wavelengths (below $420 \mathrm{~nm}$ ). The $k$-values increase as the annealing temperature increases. This may be related to the increase in surface roughness with increasing annealing temperature. The numerical values of our results for $n$ and $k$ agree with the results of Gao et al. [16] for $\mathrm{BTO}+2 \mathrm{~mol} . \% \mathrm{ZnO}$ and $6 \mathrm{~mol} . \% \mathrm{ZnO}$, Cai et al. [17], Wu et al. [18] for $\mathrm{Ba}\left(\mathrm{Ti}_{1-x} \mathrm{Ni}_{x}\right) \mathrm{O}_{3}$ thin films, and Filmetrics Tables, 2011 [19], at $400 \mathrm{~nm}$ and $700 \mathrm{~nm}$ wavelengths, Table II. 
TABLE II

A comparison of the optical constants of $\left(\mathrm{BaTiO}_{3}\right)_{0.84}\left(\mathrm{CeO}_{2}\right)_{0.16}$ thin film with published data.

\begin{tabular}{l|c|c|c|c}
\hline \hline \multirow{2}{*}{ Material } & \multicolumn{2}{|c|}{$k$} & \multicolumn{2}{|c}{$n$} \\
\cline { 2 - 5 } & $\lambda(400 \mathrm{~nm})$ & $\lambda(700 \mathrm{~nm})$ & $\lambda(400 \mathrm{~nm})$ & $\lambda(700 \mathrm{~nm})$ \\
\hline$\left(\mathrm{BaTiO}_{3}\right)_{0.84}\left(\mathrm{CeO}_{2}\right)_{0.16}$ [present data] & 0.015 & 0.0010 & 2.12 & 2.076 \\
$\mathrm{BTO}+2 \mathrm{~mol} \% \mathrm{ZnO},[16]$ & 0.025 & 0.000 & 2.00 & 2.15 \\
$\mathrm{BTO}+6 \mathrm{~mol} . \% \mathrm{ZnO},[16]$ & 0.0135 & 0.000 & 1.98 & 2.00 \\
$\mathrm{BTO}+1 \mathrm{~mol} \% \mathrm{NiO}_{2},[17]$ & 0.000 & & & \\
$\mathrm{BTO}+2 \mathrm{~mol} \% \mathrm{NiO}_{2},[17]$ & 0.008 & & & \\
$\mathrm{BTO}+5 \mathrm{~mol} \% \mathrm{NiO}_{2},[17]$ & 0.025 & & & \\
$\mathrm{BTO}+10 \mathrm{~mol}^{2} \mathrm{NiO}_{2},[17]$ & 0.043 & & & \\
\end{tabular}

The extinction coefficient $k$ is related to the absorption coefficient $\alpha$ by the relation

$$
\alpha=\frac{4 \pi k}{\lambda} \text {. }
$$

The optical band gap $\left(E_{\mathrm{g}}\right)$ values were calculated according to a direct allowed transition from the general relation $(\alpha h \nu) \propto\left(h \nu-E_{\mathrm{g}}\right)^{1 / 2}$. The calculated $E_{\mathrm{g}}$ values are listed in Table III. It shows that $E_{\mathrm{g}}$ increases from $3.68 \mathrm{eV}$ to $3.75 \mathrm{eV}$ upon annealing at $300{ }^{\circ} \mathrm{C}$. Annealing the films at temperatures above $300^{\circ} \mathrm{C}$ leads to a continuous decrease in $E_{\mathrm{g}}$ values. The increase in $E_{\mathrm{g}}$ for the films annealed at $200{ }^{\circ} \mathrm{C}$ and $300^{\circ} \mathrm{C}$ may be due to the reduction in defect centers (oxygen vacancies) as the stoichiometry improved upon oxidation. However, the decrease in $E_{\mathrm{g}}$ after the annealing at temperatures above $300^{\circ} \mathrm{C}$ may be related to the structure transformation from amorphous to crystalline [20]. Our results for $E_{\mathrm{g}}$ agree with the results of Gao et al. [16] for BTO +2 mol.\% $\mathrm{ZnO}$ and 6 mol.\% $\mathrm{ZnO}$, Wu et al. [18] for $\mathrm{Ba}\left(\mathrm{Ti}_{1-x} \mathrm{Ni}_{x}\right) \mathrm{O}_{3}$ thin films, Cai et al. [17] and Filmetrics Tables, 2011 [19], at $400 \mathrm{~nm}$ and $700 \mathrm{~nm}$ wavelengths, Table III.

TABLE III Comparison of the obtained $E_{\mathrm{g}}$ values with the published data.

\begin{tabular}{c|c|c}
\hline \hline Material & $\begin{array}{c}\text { Annealing } \\
\left.\text { temp. [ }{ }^{\circ} \mathrm{C}\right]\end{array}$ & $E_{\mathrm{g}}[\mathrm{eV}]$ \\
\hline$\left(\mathrm{BaTiO}_{3}\right)_{0.84}\left(\mathrm{CeO}_{2}\right)_{0.16}$, [present data] & as-prepared & 3.68 \\
$\left(\mathrm{BaTiO}_{3}\right)_{0.84}\left(\mathrm{CeO}_{2}\right)_{0.16}$, [present data] & 300 & 3.75 \\
$\left(\mathrm{BaTiO}_{3}\right)_{0.84}\left(\mathrm{CeO}_{2}\right)_{0.16}$, [present data] & 400 & 3.67 \\
$(\mathrm{BaTiO})_{0.84}\left(\mathrm{CeO}_{2}\right)_{0.16}$, [present data] & 500 & 3.65 \\
BTO pure, Ref. [18] & 700 & 3.56 \\
BTO pure, Ref. [18] & 900 & 3.67 \\
BTO + 1 mol.\% $\mathrm{NiO}_{2}$, Ref. [19] & & 3.58 \\
BTO + 2 mol.\% $\mathrm{NiO}_{2}$, Ref. [19] & & 3.49 \\
BTO + mol.\% $\mathrm{NiO}_{2}$, Ref. [19] & & 3.35 \\
BTO + 10 mol.\% $\mathrm{NiO}_{2}$, Ref. [19] & & 3.13
\end{tabular}

\section{Conclusions}

$\left(\mathrm{BaTiO}_{3}\right)_{0.84}\left(\mathrm{CeO}_{2}\right)_{0.16}$ thin films were prepared by e-beam evaporation and characterized by XRD, SEM, EDAX and SE. The XRD and SEM revealed the amorphous structure for the as-prepared films. Recrystallization was observed upon annealing the films at
$200{ }^{\circ} \mathrm{C}$ in air for $1 \mathrm{~h}$. The ellipsometric data from $\left(\mathrm{BaTiO}_{3}\right)_{0.84}\left(\mathrm{CeO}_{2}\right)_{0.16}$ thin films fit very well over a wide spectral range using a two-layer model. The thickness and optical constant were accurately determined with change in the annealing temperature. The refractive index showed a peak value when annealed at $300^{\circ} \mathrm{C}$, then dropped with further increase of the annealing temperature. The optical band gap showed gradual decrease with the annealing temperature. This accurate determination of the optical constants over a wide spectral range will be very useful and should be taken into consideration in designing devices using optical thin films technology.

\section{Acknowledgments}

Dr S.H. Mohamed and Prof. Dr. M. El-Hagary are acknowledged for their useful discussions and technical support. This work is supported by the Saudi Basic Industries Corporation (SABIC) and Deanship of Scientific Research at Qassim University, Saudi Arabia under the contract no. SR-S-010-10.

\section{References}

[1] C. Bi, M. Zhu, Q. Zhang, Y. Li, H. Wang, Mater. Chem. Phys. 126, 596 (2011)

[2] D.A. Tenne, A. Soukiassian, X.X. Xi, H. Choosuwan, R. Guo, A.S. Bhalla, Phys. Rev. B 70, $174302(2004)$

[3] A. Jezowski, J. Mucha, R. Pazik, W. Strek, Appl. Phys. Lett. 90, 114104 (2007)

[4] Z.G. Hu, Y.W. Li, M. Zhu, Z.Q. Zhu, J.H. Chu, Phys. Lett. A 372, 4521 (2008)

[5] S. Yoon, J. Dornseiffer, Y. Xiong, D. Grüner, Z. Shen, S. Iwaya, C. Pithan, R. Waser, J. Eur. Ceram. Soc. 31, 773 (2011)

[6] A.Y. Fasasi, B.D. Ngomb, J.B. Kana-Kana, R. Bucher, M. Maaza, C. Theron, U. Buttner, J. Phys. Chem. Solids 70, 1322 (2009).

[7] M.W. Jones, E. Jaatinen, Opt. Mater. 31, 122 (2008)

[8] M. Cernea, O. Monnereau, P. Llewellyn, L. Tortet, C. Galassi, J. Eur. Ceram. Soc. 26, 3241 (2006)

[9] A.A. Issa, N.M. Molokhia, Z.H. Dughaish, J. Phys. D, Appl. Phys. 16, 1109 (1983) 
[10] Z.H. Dughaish, A.A. Issa, J. Nat. Sci. Math. 2, 63 (2008).

[11] S.-S. Park, J.-H. Ha, H.N. Wadley, Integrat. Ferroelectr. 95, 251 (2007)

[12] S.H. Mohamed, Z.H. Dughaish, Philos. Mag. 92, 1212 (2012)

[13] A.Y. Fasasi, M. Maaza, E.G. Rohwer, D. Knoessen, Ch. Theron, A. Leitch, U. Buttner, Thin Solid Films 516, 6226 (2008).

[14] C.M. Herzinger, B. Johs, W.A. McGahan, J.A. Woollam, W. Paulson, J. Appl. Phys. 83, 3323 (1998).

[15] S.H. Mohamed, O. Kappertz, T. Niemeier, R. Drese, M.M. Wakkad, M. Wuttig, Thin Solid Films 468, 48 (2004)
[16] W.L. Gao, H.M. Deng, D.J. Huang, P.X. Yang, J.H. Chu, J. Phys., Conf. Series 276, 012163 (2011)

[17] W. Cai, C. Fu, J. Gao, Q. Guo, X. Deng, C. Zhang, Physica B 406, 3583 (2011).

[18] M. Wu, Z. Wang, T. Zhang, W.F. Zhang, Thin Solid Films 518, 7007 (2010).

[19] Filmetrics, 2011: http://www.filmetrics.com/ refractive-index-database/.

[20] S.H. Mohamed, H.M. Ali, H.A. Mohamed, A.M. Salem, Eur. Phys. J. Appl. Phys. 31, 95 (2005). 